\title{
Effect of miR-23a on anoxia-induced phenotypic transformation of smooth muscle cells of rat pulmonary arteries and regulatory mechanism
}

\author{
LI YAN $^{1,2}$, HAIXIANG GAO ${ }^{2}$, CHUNZHI LI $^{3}$, XIAOWEN HAN $^{2}$ and XIAOYONG $\mathrm{QI}^{1,4}$ \\ ${ }^{1}$ Department of Internal Medicine, Hebei Medical University, Shijiazhuang, Hebei 050017; Departments of \\ ${ }^{2}$ Respiratory Medicine, ${ }^{3}$ Infectious Diseases and ${ }^{4}$ Heart Disease Center, Hebei General Hospital, \\ Shijiazhuang, Hebei 050051, P.R. China
}

Received August 1, 2016; Accepted September 15, 2016

DOI: $10.3892 / \mathrm{ol} .2016 .5440$

\begin{abstract}
We investigated the possible implication of miR-23a in anoxia-induced phenotypic transformation of the pulmonary arterial smooth muscle and studied the mechanism of upregulation of miR-23a expression in anoxia. The collagenase digestion method was used for preparing rat primary pulmonary artery smooth muscle cell (PASMC) culture. SM-MHC, SM- $\alpha$-actin, calponin-1 and SM22 $\alpha$ protein expression levels were evaluated using western blot analysis after the ASMCs were subjected to anoxia treatment $\left(3 \% \mathrm{O}_{2}\right)$. Transfection with miR-23a mimics were conducted when PASMCs were under normoxia and anoxia conditions. EdU staining was used to detect the proliferative activity of PASMCs. Cells were transfected with HIF-1 $\alpha$ specific siRNA under anoxia condition. RT-qPCR was used to detect miR-23a expression in PASMCs. Chromatin immunoprecipitation method was employed to verify the binding sites of HIF-1 $\alpha$. The dual-luciferase reporter gene was used to study the role of HIF-1 and its binding sites. Rat hypoxic pulmonary hypertension models were established to study the expression of miR-23a using RT-qPCR method and to verify the expression of miR-23a in the arteriole of the rat pulmonary. Our results showed that compared with normoxia condition, under anoxia condition $\left(3 \% \mathrm{O}_{2}\right)$, the expression levels of the contractile phenotype marker proteins decreased significantly after 24 and $48 \mathrm{~h}$. The positive rate of the EdU staining increased significantly and the expression of miR-23a increased. Transfection with miR-23a-mimic downregulated the expression of contractile marker proteins and improved the positive rate of the EdU staining under normoxia. Anoxia and transfection with HIF-1 $\alpha$ enhanced the
\end{abstract}

Correspondence to: Dr Xiaoyong Qi, Department of Internal Medicine, Hebei Medical University, 361 Zhongshan East Road, Shijiazhuang, Hebei 050017, P.R. China

E-mail: liyan160704@163.com

Key words: anoxia-induced pulmonary arterial hypertension, anoxia, HIF-1 $\alpha$, miR-23a, phenotypic transformation, pulmonary artery smooth muscle cells activity of the wild-type Luc-miR-23a-1 (WT) reporter gene. We concluded that miR-23a participated in the anoxia-induced phenotypic transformation of PASMCs. Increased expression of miR-23a under anoxia may primarily be due to miR-23a-1 and miR-23a-3 upregulation. The anoxia-induced upregulation of miR-23a was regulated by HIF-1.

\section{Introduction}

High altitude heart disease is a common disease in people living in the high altitude areas (1). Hypoxic pulmonary hypertension (HPH) has been reported to be the key link of its onset (2). Understanding the pathogenic mechanism of HPH is the key for prevention and treatment. One of the major pathological change characteristics of HPH is hypoxic pulmonary vasoconstriction and pulmonary vascular structural remodeling (3). Hypertrophy and proliferation of pulmonary artery smooth muscle cells (PASMCs) can lead to thicker pulmonary arteriole walls and narrower inner diameter, increased pulmonary vascular resistance, and pulmonary arterial pressure (4). Long-term consistent pulmonary arterial hypertension may lead to compensatory hypertrophy of the right ventricle and even right heart failure (5).

Abnormal proliferation, apoptosis and migration of PASMCs are the most important characteristics of pulmonary vascular structural remodeling (6). Previous studies often focused on the mechanism of changes in related bioactive molecules involved in regulating functions such as proliferation, apoptosis and migration (7-9). Results obtained from other studies revealed that anoxia can significantly downregulate the expression of PASMC contractile phenotype marker proteins $(10,11)$. However, the specific mechanism of this downregulation is still unclear. Therefore, in-depth research on the molecular mechanism of phenotypic transformation of PASMCs may help us to explain the internal mechanism involved in pulmonary arterial structural modeling during the process of hypoxic pulmonary hypertension.

MicroRNAs (miRNAs) are small endogenous non-coding single stranded RNA molecules with regulatory capacities (12). It is estimated that the expression of $\sim 1 / 3$ of the human genes are regulated by miRNA (13). miRNAs can degrade mRNA (14) 
by directly binding to the 3'-UTR of its target mRNA. miRNAs can also regulate the gene expression through inhibition of mRNA translation (15). There are several studies showing that miRNAs can participate in multiple physiological processes such as cellular differentiation, metabolism, apoptosis and proliferation. Also, the involvement of miRNAs in regulation of many other pathological processes such as tumorigenesis, inflammation resolution and vascular proliferation has been reported $(16,17)$. However, little has been done to determine whether miRNAs are involved in regulation of anoxia-induced phenotypic transformation of VSMCs. The internal mechanism of anoxia-induced changes in expression of miRNA in PASMCs is also expected to be studied.

We verified the expression of a series of miRNAs using RT-qPCR in anoxia-induced phenotypic transformation models of PASMCs. Additionally, we verified whether miR-23a upregulation was involved in anoxia-induced phenotypic transformation of PASMCs.

\section{Materials and methods}

Isolation and purification of the primary PASMCs in rats. Healthy SPF Sprague-Dawley (SD) rats weighing 180 g were provided by the Inner Mongolia Medical University of Inner Mongolia Medical University (Inner Mongolia, China; animal license no. SCXK Meng 2014-0007). Ethics approval for the animal experiments was received from the Animal Ethics Committee of Inner Mongolia Medical University Animal Center. Rats were decollated after they were anesthetized by intraperitoneal injections of $10 \%$ urethane $(1 \mathrm{ml} / 100 \mathrm{~g})$ (Beijing Chemical Reagent Co., Ltd., Beijing, China). Rats were fixed and transferred to an aseptic operation room. Thoracic cavity was dissected and heart and lung were extracted and immersed in pre-cooled sterilized phosphate-buffered saline (PBS). Starting from right ventricle, the arteriole was separated from the lung. The fibrous tissue and adipose tissue were removed from the outer membrane of the pulmonary arteries with bended microscopic tweezers (Beijing Beifang Biologic Technology Research Institute, Beijing, China). Blood vessels were longitudinally cut open and washed twice with D-Hank's solution (Invirogen Life Technologies, Carlsbad, CA, USA). The inner membrane surface of the blood vessels was exposed and the vascular endothelial cells were removed. The remaining tissue was sliced into fragments and placed in a centrifuge tube containing $0.2 \%$ collagenase I (Sigma-Aldrich, St. Louis, MO, USA). It was agitated gently and digested for $3 \mathrm{~h}$ at $37^{\circ} \mathrm{C}$. It was then centrifuged at $800 \mathrm{x} \mathrm{g}$ for $5 \mathrm{~min}$ and the supernatant was discarded. The pellet was re-suspended in $5 \mathrm{ml}$ of high glucose Dulbecco's modified Eagle's medium (DMEM), containing 10\% fetal bovine serum (FBS) (both from Gibco-BRL, Grand Island, NY, USA; Invitrogen Life Technologies). It was then incubated at $37^{\circ} \mathrm{C}$ with $5 \% \mathrm{CO}_{2}$ for 3 days. Culture media were changed every 3 days.

Identification of PASMCs. Cells were placed in suspension, inoculated into a sterile 24-well microplate and allowed to stand for 2 days. The cells were rinsed 3 times with pre-heated $\left(37^{\circ} \mathrm{C}\right) \mathrm{PBS}$ for $3 \mathrm{~min}$ (each time). Cells were fixed with $200 \mu \mathrm{l}$ of $4 \%$ paraformaldehyde (Beijing Chemical Reagent Co., Ltd.) for $15 \mathrm{~min}$, followed by washing with
PBS 3 times (10 min each). One hundred microliters of $0.3 \%$ Triton X-100 (Invitrogen, Darmstadt, Germany) was added to rupture the membrane for $30 \mathrm{~min}$ at room temperature. The cells were rinsed 3 times with PBS (10 min each) and blocked for $30 \mathrm{~min}$ at room temperature after adding $100 \mu \mathrm{l}$ of $10 \%$ goat serum (Invitrogen). Blocking buffer was discarded and the cells were incubated at $4{ }^{\circ} \mathrm{C}$ overnight after the addition of $100 \mu \mathrm{l}$ of specific SM- $\alpha$-actin antibody (dilution ratio of 1:200; Abcam, Cambridge, UK). The cells were then rinsed 3 times with PBS (10 min each) and incubated at $37^{\circ} \mathrm{C}$ for $60 \mathrm{~min}$ in the dark and washed 3 times with PBS (10 min each) after the addition of $100 \mu \mathrm{l}$ of FITC-marked secondary antibody (dilution ratio of 1:300; Bioss Biological Technology Co., Beijing, China). The cells were incubated for $5 \mathrm{~min}$ at room temperature followed by the addition of the DAPI nucleus staining solution (Wuhan Boster Bio-Engineering Co., Ltd., Wuhan, China) and rinsed 3 times with PBS (10 min each time). The samples were mounted with the anti-fluorescent quenching mounting medium (Bioss Biological Technology Co.) and were kept in the dark. The cells were then studied under a laser confocal microscope (Olympus, Tokyo, Japan).

Protein expression. The primary rat PASMCs were rinsed with preheated PBS $\left(37^{\circ} \mathrm{C}\right)$. Pre-cooled lysing buffer was then added. The adherence cells were removed from the ice with a cell scraper and placed on ice. After $20 \mathrm{~min}$ of lysis, samples were centrifuged at $10,000 \mathrm{x}$ g for $5 \mathrm{~min}$ at $4^{\circ} \mathrm{C}$. The supernatant was collected for BCA protein quantification (Gemini Bio-Products, Woodland, CA, USA). Loading buffer was added to samples and they were prepared for SDS-PAGE. Proteins were then transferred onto a PVDF membrane (Invitrogen Life Technologies) for $60 \mathrm{~min}$ at a constant voltage of $16 \mathrm{~V}$. The membrane was immersed into 5\% BSA blocking buffer for $2 \mathrm{~h}$ and after rinsing antibody diluent TBST was added $\left(0.1 \mathrm{ml} / \mathrm{cm}^{2}\right)$. It was incubated overnight at $4^{\circ} \mathrm{C}$. Anti-SM-MHC, anti-SM- $\alpha$-actin, anti-calponin-1, anti-SM22 $\alpha$ and anti- $\beta$-actin antibodies (dilution ratio of 1:1,000; Abcam) was added to membranes. Membranes were then washed 3 times with TBST (10 min each), and incubated with HRP-marked goat anti-rabbit secondary antibody (1:5,000; cat no.: 10672), HRP-marked goat anti-mouse secondary antibody (1:5,000; cat no.: 10541) and HRP-marked rabbit anti-goat secondary antibody (1:5,000; cat no.: 12376) (all from Wuhan Boster Bio-Engineering Co., Ltd) for $1 \mathrm{~h}$ at room temperature and rinsed 3 times (10 min each) with TBST. Finally, chemiluminescence reagent (Millipore, Billerica, MA, USA) was added and membranes were placed in darkroom for exposure. The quantity one software (Tree Star, Inc., Ashland, OR, USA) was employed for imaging. The relative gray value was used to express the relative protein content.

Detecting proliferation of PASMCs with EdU. PASMCs were inoculated into a 96 -well microplates $\left(1 \times 10^{4} /\right.$ well). The cells were placed in a normoxia-preconditioned incubator and were grown until they entered a normal growth stage. Cells in the anoxia treatment group were placed in an anoxia incubator and cultured for $48 \mathrm{~h}$ (H48h). Cells in the normoxia group were placed in a normoxia incubator and cultured for $48 \mathrm{~h}$ (N48h). EdU solution (Premier Biosoft International, Palo Alto, CA, USA) was diluted proportionally with the culture medium 
for preparation of $50 \mu \mathrm{M}$ EdU culture medium. One hundred microliters of EdU culture medium $(50 \mu \mathrm{M})$ was added to each well. Culture medium was discarded after $2 \mathrm{~h}$. The cells were washed twice with PBS (5 min each time). Paraformaldehyde (60 $\mu \mathrm{l})(4 \mathrm{v} \%)$ (Beijing Chemical Reagent Co., Ltd.) was added to each well, followed by $30 \mathrm{~min}$ incubation at room temperature. Glycine $(50 \mu \mathrm{l})(2 \mathrm{mg} / \mathrm{ml})$ (Invitrogen Dynal AS, Oslo, Norway) was added to each well and cells were incubated for $5 \mathrm{~min}$ on a shaking table (Thermo Fisher Scientific, Inc., Waltham, MA, USA). Glycine solution was then discarded and the cells were washed for 5 min with PBS. Penetrant $(100 \mu \mathrm{l})(0.3 \%$ Triton X-100) (Invitrogen) was added to each well and cells were incubated for $10 \mathrm{~min}$ followed by a wash with PBS for $5 \mathrm{~min}$. Then, 1X Apollo ${ }^{\circledR}$ staining reaction solution $(100 \mu \mathrm{l})$ was added to each well followed by $30 \mathrm{~min}$ incubation in the dark at room temperature. Staining reaction solution was discarded and $100 \mu \mathrm{l}$ of methyl alcohol (Beijing Beifang Biotechnology Research Institute) was added to each well. The cells were washed twice with PBS (5 min each time). Hoechst 33342 (1X) reaction solution (100 $\mu \mathrm{l})$ (BD Biosciences, Mountain View, CA, USA) was added to each well and cells were incubated for $30 \mathrm{~min}$ at room temperature in the dark. The cells were washed twice with PBS and then $50 \mu 1$ goat serum (10\%) was added to each well. Subsequently, the cells were blocked for $30 \mathrm{~min}$ at room temperature. Specific SM- $\alpha$-actin antibody (50 $\mu \mathrm{l})$ (dilution of 1:200; Abcam), was added and incubated overnight at $4^{\circ} \mathrm{C}$. Cells were rinsed 3 times with PBS (10 min each). FITC marked secondary antibody (Wuhan Boster Bio-Engineering Co., Ltd.) (dilution of 1:300) was added followed by $60 \mathrm{~min}$ incubation at $37^{\circ} \mathrm{C}$ in the dark followed by 3 washes with PBS (10 min each). Cells were kept in the dark, before observation with laser confocal microscope after dropwise addition of an appropriate volume of the anti-quenching mounting medium (Wuhan Boster Bio-Engineering Co., Ltd.).

miR-23a detection using RT-qPCR. The PASMC cells were cultured in 6-well microplates. The microplate was placed on ice and $800 \mu 1$ of pre-cooled RNAiso Plus (Qiagen, Inc., Valencia, CA, USA) was added to each well. Adherent cells were removed and transferred into an Eppendorf tube. After $10 \mathrm{~min}$, samples were centrifuged at $12,000 \mathrm{x}$ g for $5 \mathrm{~min}$ at $4^{\circ} \mathrm{C}$. Supernatant was collected and RNAiso Plus chloroform (Qiagen, Inc.) was added and cells were left for $5 \mathrm{~min}$ and centrifuged at $12,000 \mathrm{x}$ g for $15 \mathrm{~min}$ at $4^{\circ} \mathrm{C}$. Supernatant was collected and isopropanol (Qiagen, Inc.) was added, and cells were left for $10 \mathrm{~min}$ at room temperature followed by centrifugation at $12,000 \mathrm{x}$ g for $10 \mathrm{~min}$ at $4^{\circ} \mathrm{C}$. Supernatant was discarded, and pellet was dried before adding $1 \mathrm{ml}$ of $75 \%$ ethanol. Samples were centrifuged again at $12,000 \mathrm{x} \mathrm{g}$ for $5 \mathrm{~min}$ at $4^{\circ} \mathrm{C}$. Supernatant was discarded, and pellet was dissolved in DEPC-treated water (Qiagen, Inc.). For reverse transcriptional we used All-in-One ${ }^{\mathrm{TM}}$ miRNA First-Strand cDNA Synthesis kit (Takara Bio, Inc., Japan).

RT reaction system was: $1 \mu \mathrm{l}(100 \mathrm{ng})$ total RNA, $2.5 \mathrm{U} / \mu \mathrm{l}$ Poly(A) polymerase $(0.2 \mu \mathrm{l})$, RTase mix $(0.2 \mu \mathrm{l}), 5 \mathrm{X}$ reaction buffer $(1 \mu \mathrm{l})$ and nuclease-free water $(2.6 \mu \mathrm{l})$. RT reaction conditions were: $37^{\circ} \mathrm{C}$ for $60 \mathrm{~min} ; 85^{\circ} \mathrm{C}$ for $5 \mathrm{~min}$. Reverse transcription products were diluted with non-enzymatic sterile $\mathrm{ddH}_{2} \mathrm{O}$.
The qPCR reaction system was: $5 \mu \mathrm{l}$ of $2 \mathrm{X}$ All-in-One qPCR mix, $1 \mu \mathrm{l}(2 \mu \mathrm{M})$ of All-in-One miRNA qPCR primer, $1 \mu \mathrm{l}(2 \mu \mathrm{M})$ universal adaptor PCR primer, $1 \mu \mathrm{l}$ (diluted 1:5) First-Strand cDNA and $2 \mu \mathrm{l}$ nuclease-free water.

PCR condition was as follows: Pre-denaturation at $95^{\circ} \mathrm{C}$ for $10 \mathrm{~min} ; 95^{\circ} \mathrm{C}$ for $10 \mathrm{sec}, 60^{\circ} \mathrm{C}$ for $20 \mathrm{sec}$ and $72^{\circ} \mathrm{C}$ for $10 \mathrm{sec}$ and total cycles were 40 . Dissolution curve reaction was $65^{\circ} \mathrm{C}$ for $5 \mathrm{sec}$, fluorescence collection; the temperature in each cycle increased by $0.5^{\circ} \mathrm{C}$, up to $95^{\circ} \mathrm{C}$.

Cell transfection. The PASMCs were cultured for $24 \mathrm{~h}$ with DMEM containing $0.5 \%$ FBS before transfection. Cells transfected with miR-23a inhibitor (100 nM) (Qiagen, Inc.) were designated as the miR-23a inhibitor group.

Cells that transfected with inhibitor control (100 nM) (Qiagen, Inc.) were designated as the inhibitor control (ctrl) group, and cells with transfection reagent (equal volume) were designated as the vehicle group. All the groups were placed in an anoxia incubator containing $3 \% \mathrm{O}_{2}$ and were incubated for 48 h. Cells transfected with miR-23a mimic (100 nM) were designated as the miR-23a mimic group, and cells transfected with mimic control $(100 \mathrm{nM})$ were designated as the mimic ctrl group. Cells with transfection reagent (equal volume) were designated as the blank control group, or vehicle. All groups were incubated in a normoxia incubator containing $21 \% \mathrm{O}_{2}$ for $48 \mathrm{~h}$.

Detecting the expression of myocardin and miR-23a in the pulmonary arteriole tissue with RT-qPCR. PASMCs $\left(10^{6}\right)$ were directly added to $1 \mathrm{ml}$ RNAiso Plus. The pulmonary arteriole tissue was placed in a glass homogenizer. Five hundred microliters of pre-cooled RNAiso Plus was added. Tissue was sufficiently grounded and then mixed in a vortex mixer and allowed to stand for $5 \mathrm{~min}$ at room temperature. Then, $1 / 5$ volume of chloroform was added and mixed well for $1 \mathrm{~min}$, allowed to stand for $5 \mathrm{~min}$ and centrifuged at $10,000 \mathrm{x} \mathrm{g}$ for $15 \mathrm{~min}$ at $4^{\circ} \mathrm{C}$. An equal volume of isopropanol was added and after mixing it was left for $5 \mathrm{~min}$ at room temperature, followed by centrifugation at $10,000 \mathrm{x} \mathrm{g}$ for $10 \mathrm{~min}$ at $4^{\circ} \mathrm{C}$. Supernatant was discarded, and $1 \mathrm{ml}$ of $75 \%$ ethanol was added to the pellet. An appropriate volume of DEPC water was added for sufficient dissolution and precipitation.

The reaction system was $25 \mu$ : The fluorescent RT-PCR reaction solution was $1 \mu \mathrm{l}$ DNA polymerase, $0.35 \mu 1$ reverse transcriptase and $5 \mu$ template RNA. Solution was mixed well and centrifuged at 5,000 x g for $10 \mathrm{sec}$. Real-time fluorescent RT-PCR amplification procedure was as follows: Reverse transcription for $30 \mathrm{~min}$ at $50^{\circ} \mathrm{C}$; pre-denaturation for $3 \mathrm{~min}$ at $95^{\circ} \mathrm{C}$; denaturation for $15 \mathrm{sec}$ at $95^{\circ} \mathrm{C}$; annealing at $50^{\circ} \mathrm{C}$ for $30 \mathrm{sec}$; extention for $30 \mathrm{~min}$ at $72^{\circ} \mathrm{C}, 5$ cycles in total; denaturation for $10 \mathrm{sec}$ at $95^{\circ} \mathrm{C}$; annealing for $40 \mathrm{sec}$ at $55^{\circ} \mathrm{C}, 40$ cycles in total. The primer sequences were as follows: miR-23a forward, 5'-CAGGCGGGTAGTAGATG-3' and reverse, 5'-AGGGACGGGCATGGAAAGG-3'.

Pri-miR-23a-1, pri-miR-23a-2, and pri-miR-23a-3 expression. Takara fluorescent quantitation reverse transcription reagent kit and SYBR-Green $\mathrm{APCR}$ reagent (Takara Bio, Inc.) were used. Specific reaction system and conditions 
were as follows: i) $2 \mu 1$ reverse transcription reaction system PrimeScript $^{\mathrm{TM}}$ buffer (5X), $0.5 \mu 1$ PrimeScript $^{\mathrm{TM}}$ RT enzyme mix I, $0.5 \mu \mathrm{l}$ Oligo(dT) primer, $0.5 \mu 1$ random 6 mers, $500 \mathrm{ng}$ total RNA and up to $10 \mu \mathrm{l}$ RNase-free water. Reaction conditions for reverse transcription was $37^{\circ} \mathrm{C}$ for $30 \mathrm{~min}$ and $85^{\circ} \mathrm{C}$ for $5 \mathrm{~min}$. PCR reaction system was: $10 \mu \mathrm{l} \mathrm{SYBR}$ Premix Ex Taq (2X), $0.5 \mu 1$ forward primer $(10 \mu \mathrm{M}), 0.5 \mu 1$ reverse primer $(10 \mu \mathrm{M}), 0.8 \mu \mathrm{l} \mathrm{RT}$ and up to $20 \mu \mathrm{l}$ nuclease-free water. PCR reaction conditions: $95^{\circ} \mathrm{C}$ for $1 \mathrm{~min} ; 95^{\circ} \mathrm{C}$ for $5 \mathrm{sec} ; 60^{\circ} \mathrm{C}$ for $30 \mathrm{sec}$ (40 cycles). Dissolution curve reaction: $65^{\circ} \mathrm{C}$ for $6 \mathrm{sec}$, temperature increased by $0.5^{\circ} \mathrm{C}$ in each cycle, up to $95^{\circ} \mathrm{C}$. Sequence of the primers used were as follows: Pri-miR-23a-1 forward, 5'-TTCCATATGCTGACCTCCA-3' and reverse, 5'-CAAGGTACCAGGCCCTCT-3'; pri-miR-23a-2 forward, 5'-GAGGACTATGCTGTGACCAA-3' and reverse, 5'-AGCA ATGCATGCCTTTCTGGT-3'; pri-miR-23a-3 forward, 5'-GCC GTAGTCACTCTTTGGTT-3' and reverse, 5'-TCGATCGTGC AAGTTGTTAGA-3'.

Chromatin immunoprecipitation (ChIP). We closely followed the instructions provided with the ChIP kit (Millipore). The PASMCs were properly cultured with high glucose DMEM containing $10 \%$ FBS until cell density reached $80-90 \%$. They were cross linked for $15 \mathrm{~min}$ at room temperature after addition of $1 \%$ formaldehyde. Culture medium and glycine was added to terminate cross-linking. Cells were transferred to an Eppendorf tube and centrifuged at 1,000 x $\mathrm{g}$ for $5 \mathrm{~min}$ at $4^{\circ} \mathrm{C}$. Cells were re-suspended with SDS lysis buffer and ruptured with ultrasound and the sediment was collected. Nine hundred microliters dilution buffer $+9 \mu 1$ protease inhibitor cocktail I (PIC; 100X) was added to each $100 \mu \mathrm{l}$ of the ultrasonic lysis products. Sixty microliters of the protein $\mathrm{G}$ agarose was added to each tube. It was well mixed and placed at $4^{\circ} \mathrm{C}$ for $1 \mathrm{~h}$ followed by centrifugation at 3,000-5,000 x g for $1 \mathrm{~min}$. Nine hundred microliters of the supernatant were transferred to a new tube and appropriate antibody was added. For negative control we used $5 \mu \mathrm{lgG}$. In the experimental group, we used $5 \mu \mathrm{l}$ HIF-1 $\alpha$ polyclonal antibody. Sixty microliters of the protein $\mathrm{G}$ and agarose was added to each tube, and incubated at $4^{\circ} \mathrm{C}$ for $1 \mathrm{~h}$ with gentle shaking to collect the HIF-1 $\alpha / \mathrm{miR}-23 \mathrm{a}$ gene compound and the HIF-1 $\alpha$ antibody followed by centrifugation at $3,000 \mathrm{x} \mathrm{g}$ at $4^{\circ} \mathrm{C}$ for $1 \mathrm{~min}$. Supernatant was discarded after the agar was precipitated. It was incubated at $4^{\circ} \mathrm{C}$ for $5 \mathrm{~min}$ and DNA bound to HIF-1 $\alpha$ was eluted. After addition of $1 \mu 1$ RNase A, it was incubated at $37^{\circ} \mathrm{C}$ for $30 \mathrm{~min}$. Four microliters of $0.5 \mathrm{M}$ EDTA, $8 \mu \mathrm{l}$ $1 \mathrm{M}$ Tris- $\mathrm{HCl}$, and $1 \mu \mathrm{l}$ proteinase $\mathrm{K}$, were added followed by incubation at $45^{\circ} \mathrm{C}$ for $2 \mathrm{~h}$. TE was added then to adjust the volume at $250 \mu \mathrm{l}$. After the addition of $250 \mu \mathrm{l}$ of phenol chloroform mixture, it was centrifuged at $11,000 \mathrm{x} g$ for $7 \mathrm{~min}$. The upper aqueous phase was transferred to an Eppendorf tube and of equal volume of chloroform isoamylol mixture was added. They were mixed well and centrifuged at 11,000 x g for $5 \mathrm{~min}$. The supernatant was transferred to an Eppendorf tube, and $1 / 10$ volume of $3 \mathrm{M}$ sodium acetate $(\mathrm{pH}$ 5.2) and $1 \mu 1$ of $20 \mathrm{mg} / \mathrm{ml}$ glycogen were added. It was mixed well, and 2 volume of ethanol was added and after mixing it was transferred to $-20^{\circ} \mathrm{C}$ for $1 \mathrm{~h}$ to precipitate DNA. Sample was then centrifuged at $13,000 \mathrm{xg}$ for $10 \mathrm{~min}$ at $4^{\circ} \mathrm{C}$. The supernatant was discarded and $700 \mu \mathrm{l}$ of $70 \%$ ethanol was used to wash the sediment. Fifty microliters of TE was added to dissolve the sediment.

PCR reaction system: $10 \mu \mathrm{lSYBR}{ }^{\circledR}$ Premix Ex Taq GC (2X), $0.4 \mu \mathrm{l}$ forward primer $(10 \mu \mathrm{M}), 0.4 \mu \mathrm{l}$ reverse primer $(10 \mu \mathrm{M})$, $1 \mu \mathrm{l}$ DNA template and up to $20 \mu \mathrm{l}$ nuclease-free water.

PCR reaction condition: $95^{\circ} \mathrm{C}$ for $1 \mathrm{~min} ; 95^{\circ} \mathrm{C}$ for $5 \mathrm{sec}$; $60^{\circ} \mathrm{C}$ for $30 \mathrm{sec}\left(40\right.$ cycles). Dissolution curve reaction: $65^{\circ} \mathrm{C}$ for $6 \mathrm{sec}$, fluorescence collection; temperature increased by $0.5^{\circ} \mathrm{C}$ in each cycle, up to $95^{\circ} \mathrm{C}$. PCR primers: miR-23a-1R 1 forward, 5'-GGATTTTGCGTACCACCAAA-3' and reverse, 5'-CTCATTAAGGCCACTTTTCA-3'; miR-23a-1R2 forward, 5'-AAAAACTGTGCGTATGAGAG-3' and reverse, 5'-GTCC GTGCGTACACATCAAG-3'; miR-23a-1R3 forward, 5'-GTAT GTGTGCGCCTGAAGAC-3' and reverse, 5'-CGATGCAAC CTGAACCCACT-3'; miR-23a-3R forward, 5'-GTCACACTGT CGTCCGGTCC-3' and reverse, 5'-TCTGTTGCGTCGTCAC AGCTA-3'.

Dual-luciferase reporter gene experiment. Expression plasmids and the luciferase reporter gene plasmids were diluted $(100 \mathrm{ng} / \mu \mathrm{l})$. Internal reference plasmids were also diluted $(10 \mathrm{ng} / \mu \mathrm{l})$. For transfection, we followed the instruction provided by Lipofectamine 2000 kit.

For dual-luciferase reporter gene detection we used the Dual-Luciferase Reporter Assay System kit (Promega, Madison, WI, USA). Culture medium was discarded and cells were rinsed twice in PBS. Thirty microliters of freshly-prepared reporter gene cell lysis buffer 1X PLB was added to the cells in each well. Cells were lysed for $15 \mathrm{~min}$ at room temperature and then centrifuged and supernatant was collected. Twenty microliters of the supernatant was transferred to an Eppendorf tube in order to measure luciferase activity.

Mean pulmonary arterial pressure (MPAP) and right ventricular weight index $[R V /(L V+S)]$. Rats in chronic hypoxia $(\mathrm{CH})$ group were exposed to 21 days of hypoxia and rats in the normoxia control (NC) group were put in a hypobaric chamber and outside of the chamber at a simulated altitude of 5,000 m (Thermo Fisher Scientific, Inc.). Eight rats were selected from each group.

Each rat was intraperitoneally injected with $10 \%$ urethane $(1 \mathrm{ml} / 100 \mathrm{~g})$ and fixed onto a platform for separating the right external jugular vein. Each rat was intravenously injected with $0.5 \%$ heparin normal saline solution $(0.2 \mathrm{ml} / 100 \mathrm{~g}$ body mass $)$ (Beijing Sanyao Science and Technology Development Co., Ltd., Beijing, China). Right ventricle and pulmonary arterial intubations $(0.45 \mathrm{~mm}$ ID and $0.8 \mathrm{~mm}$ OD) were performed for 10 min. mPAP was determined with the Power lab multilead physiological recording instrument (Thermo Fisher Scientific, Inc.). Rats were sacrificed and thoracotomy was performed to remove the heart. The heart atrium and connective tissue were carefully separated. RV free wall was separated along the ventricular septum. The weight index of the right ventricle was calculated using the following formula: [weight of right ventricle/(left ventricle + ventricular septum) weight].

Hematoxylin and eosin $(H \& E)$ staining. Frozen sections were warmed for $60 \mathrm{~min}$ at room temperature, fixed for $15 \mathrm{~min}$ in the pre-cooled acetone at $4^{\circ} \mathrm{C}$, rinsed for $3 \mathrm{~min}$ with distilled water. The sample was stained for $5 \mathrm{~min}$ in the hematoxylin 
A

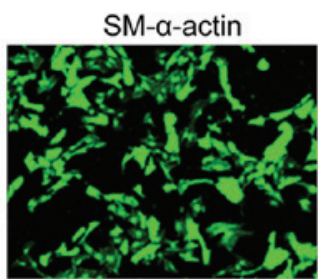

B

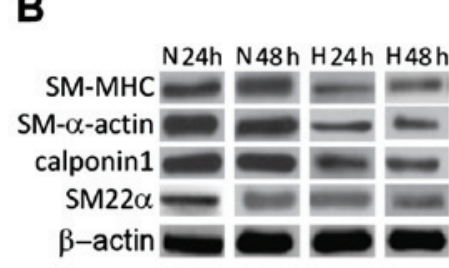

C

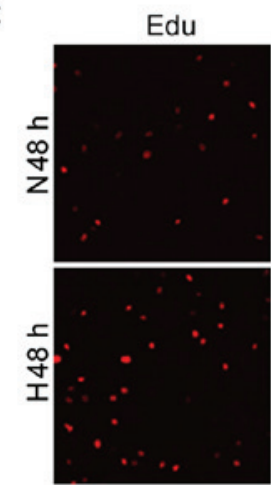

DAPI
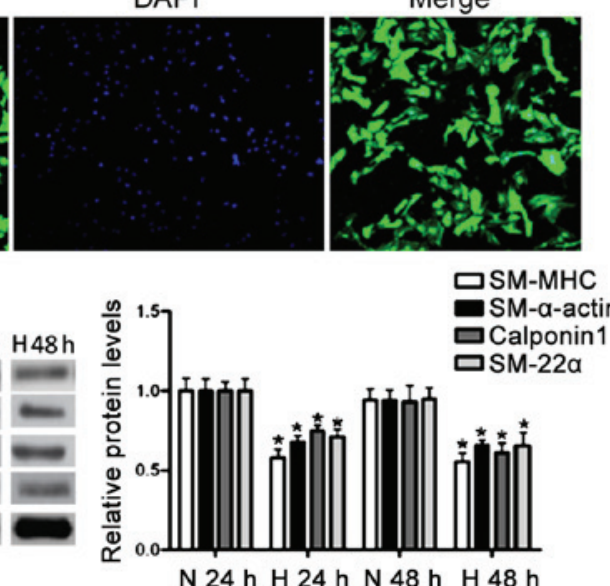

D

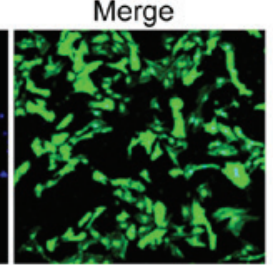

口SM-MHC 口SM-MHC 口Calponin 1

$\mathrm{N} 24 \mathrm{~h} \mathrm{H} 24 \mathrm{~h} \mathrm{~N} 48$ h H 48 h

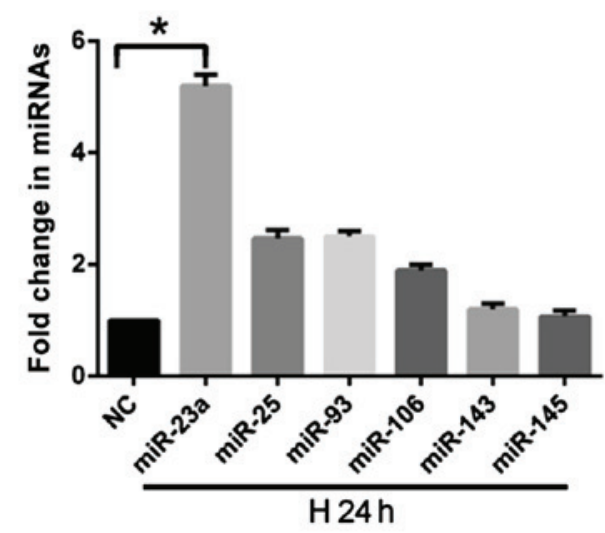

E
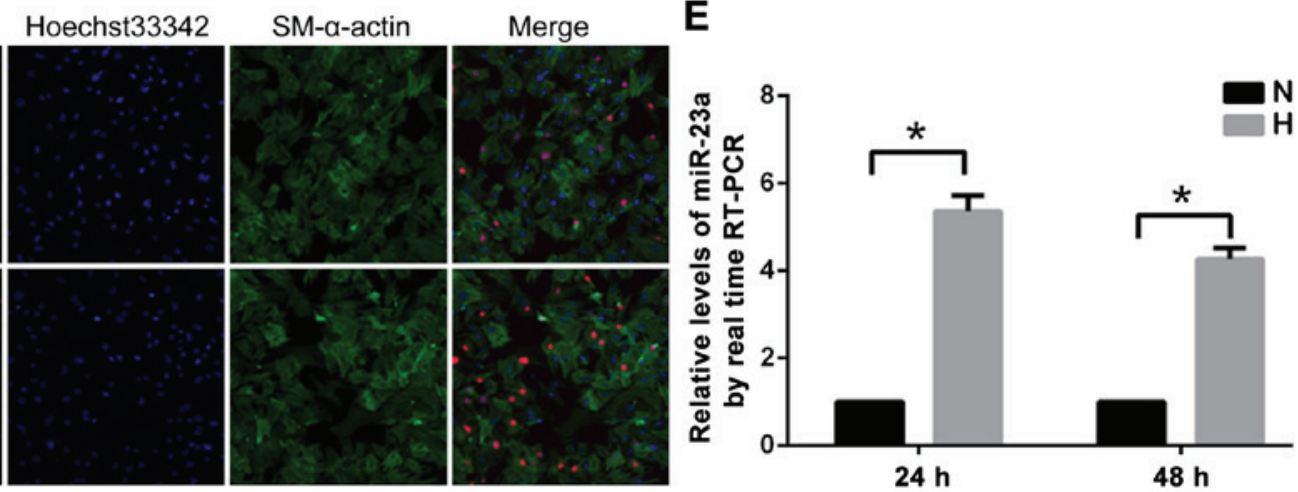

Figure 1. Effect of anoxia on the general characteristics of rat PASMCs and screening of differentiated miRNA. (A) Identifying PASMCs (x200) with SM- $\alpha$-actin immunofluorescent staining. (B) Detecting the expression of SM-MHC, SM- $\alpha$-actin, calponin-1 and SM22 $\alpha$ proteins with western blot analysis. Based on a comparison with the control group, ${ }^{*} \mathrm{P}<0.05$. (C) Detecting the proliferative activity of PASMCs with EdU staining. (D) Differential expression of miRNA at $24 \mathrm{~h}$ after anoxia. (E) Expression of miR-23a at 24 and $48 \mathrm{~h}$ after anoxia. ${ }^{*}$ Compared to the control group, P<0.05. PASMCs, pulmonary artery smooth muscle cells.

staining solution (Beijing Beifang Biologic Technology Research Institute) and then rinsed once with water, prior to being placed in $95 \%$ ethanol for $5 \mathrm{sec}$ and stained for approximately $1 \mathrm{~min}$ in the eosin solution (Beijing Beifang Biologic Technology Research Institute). The sample was then immersed in $95 \%$ ethanol for $2 \mathrm{~min}$, transferred to xylene, mounted with central gum, and observed under a microscope (Takara, Bio, Inc.). The nucleus was stained in blue while the cytoplasm was pink or red. Image analysis was studied with an inverted microscope. Outer diameter, wall thickness and intima-media thickness were measured.

Statistical analysis. SPSS 19.0 (SPSS, Inc., Chicago, IL, USA) software was used for statistical analysis. Experimental data were expressed as mean \pm standard deviation (mean \pm SD). Independent sample test was used to compare the means of the two samples. $\mathrm{P}<0.05$ was considered to indicate a statistically significant difference.

\section{Results}

Effect of anoxia on the general characteristics of rat PASMCs. Primary rat PASMC cells were growing on the culture flask wall in an extended form, most cells were fusiform, the cytoplasm was rich and cytoplasmic density was high. Sheaf-like parallel arrangement was observed, also peak-valley distribution with VSMCs characteristics was observed. After immunofluorescent staining using SM- $\alpha$-actin antibody, we observed bright green filamentous fluorescence in the cytoplasm (Fig. 1A). The positive rate of SM- $\alpha$-actin was over $95 \%$ on average. The PASMCs in the $\mathrm{NC}$ group and anoxia $\left(3 \% \mathrm{O}_{2}\right.$, 24 or $48 \mathrm{~h}$ ) treatment group were subjected to SM-MHC, SM- $\alpha$-actin, calponin- 1 and SM22 $\alpha$ detection. The result indicated that the expression levels of SM-MHC, SM- $\alpha$-actin, calponin-1 and SM22 $\alpha$ in the H24h group were significantly lower than those in the NC group $(\mathrm{P}<0.05)$ (Fig. 1B). The level of contractile phenotype marker proteins in the PASMCs at $48 \mathrm{~h}$ after anoxia treatment (H48h) was significantly lower than that in the control group (N48h). The proliferative activity of the primary PASMCs were subjected to normoxia treatment and those subjected to $3 \% \mathrm{O}_{2}$ anaerobic treatment were detected with the EdU staining method. The positive rate of EdU staining at $48 \mathrm{~h}(\mathrm{H} 48 \mathrm{~h})$ after anoxia treatment was lower than that in the $\mathrm{NC}$ group, indicating that the anoxia treatment could significantly strengthen the proliferative activity of PASMCs (Fig. 1C).

miR-23a, miR-25, miR-23a-3, and miR-106b expression levels at $24 \mathrm{~h}$ after anoxia (H24h) were compared with those in the NC group (Fig. 1D and E). The increase in miR-23a expression was the most significant. It was 5.3-fold higher 
A
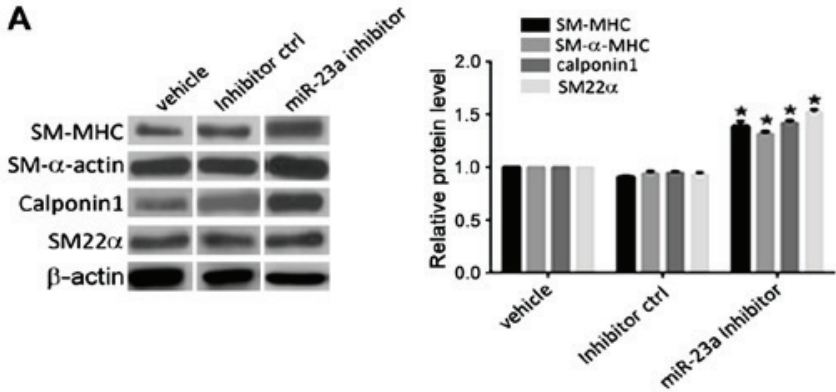

C

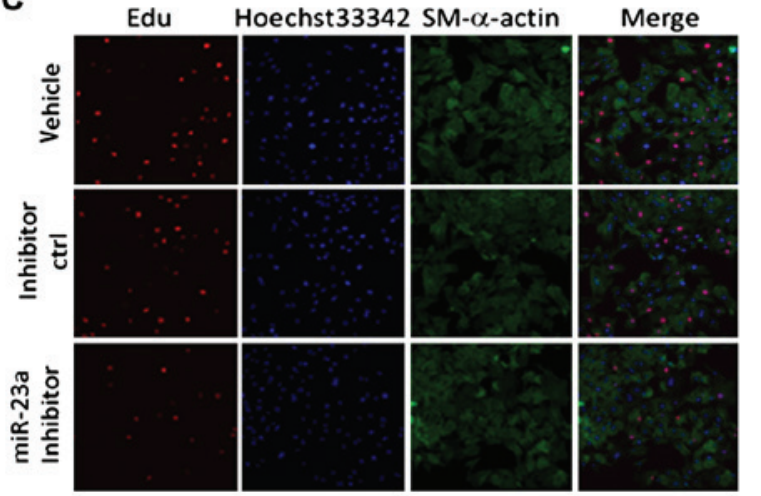

B
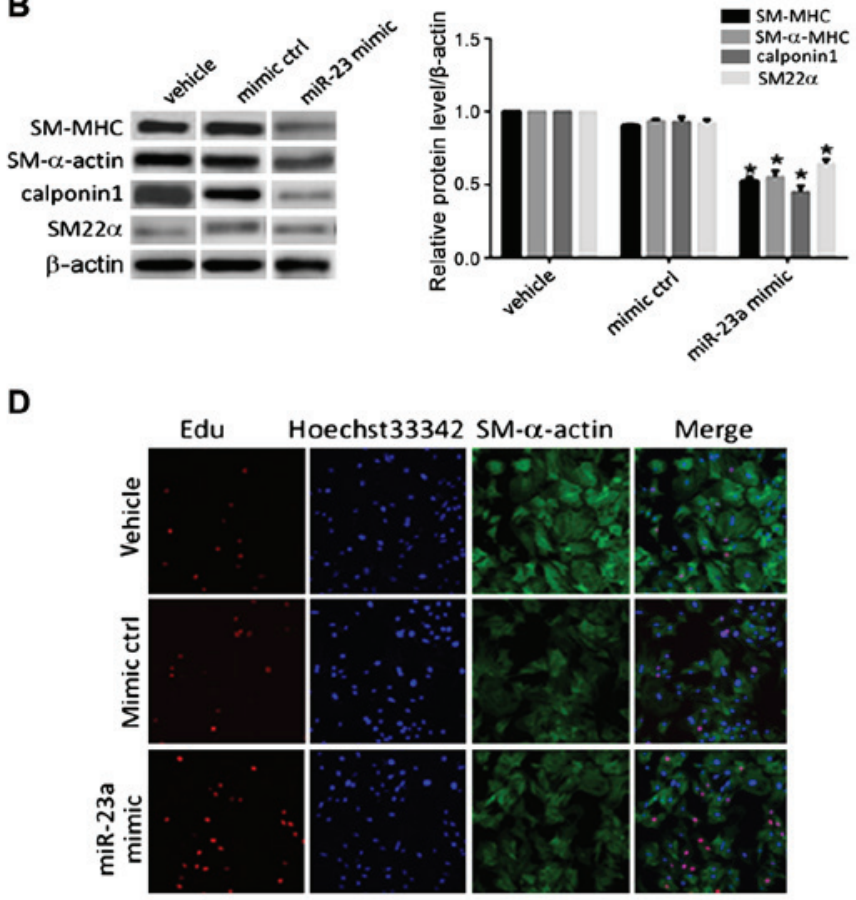

Figure 2. Role of miR-23a in anoxia-induced downregulation of the contractile phenotype marker proteins in PASMCs. (A) Detecting the expression of the SM-MHC, SM- $\alpha$-actin, calponin-1 and SM22 $\alpha$ proteins with western blot analysis. Compared to the control group, ${ }^{*}<<0.05$. (B) Detecting the expression of the SM-MHC, SM- $\alpha$-actin, calponin-1 and SM22 $\alpha$ proteins with western blot analysis with $\beta$-actin as the internal reference protein. Based on a comparison with the control group, ${ }^{*} \mathrm{P}<0.05$. (C) Detecting the proliferative activity of PASMCs transfected with miR-23a inhibitor under anoxia by means of EdU staining. (D) Detecting the proliferative activity of PASMCs transfected with miR-23a mimic under normoxia by means of EdU staining. PASMCs, pulmonary artery smooth muscle cells

than that in the NC group (N24h). No significant changes in the expression of miR-143 and miR-145 were observed. The expression level of miR-23a at $48 \mathrm{~h}$ after anoxia was detected. The result indicated that the expression level of miR-23a at $48 \mathrm{~h}$ after anoxia (H48h) was $\sim 4$-fold higher than that in the $\mathrm{NC}$ group (N48h).

Role of miR-23a in anoxia-induced downregulation of the expression of contractile phenotype marker protein in PASMCs. As shown in Fig. 2, there were no significant change in the levels of contractile marker proteins (SM-MHC, SM- $\alpha$-actin, calponin-1 and SM22 $\alpha$ ) in the control group (inhibitor ctrl) under anoxia. Contractile marker proteins were significantly upregulated after transfection with the miR-23a inhibitor. Expression of the contractile phenotype marker gene protein in VSMCs in the transfection mimic control group (mimic ctrl) demonstrated no significant changes compared to that in the blank control (vehicle) group. The expression levels of the contractile marker proteins in the PASMCs at $48 \mathrm{~h}$ after transfection with miR-23a mimic were downregulated to different extents compared with those in the transfection mimic control group. The positive rate of the staining result of PASMCs transfected with miR-23a inhibitor under anoxia was detected. It was found that the positive rate of the EdU in PASMCs in the transfection inhibitor control group (inhibitor ctrl) had no significant difference compared with that in the blank control (vehicle) group. The positive rate of the EdU staining result of the PASMCs in the transfection inhibitor control group (inhibitor ctrl) at $48 \mathrm{~h}$ after transfection with miR-23a inhibitor decreased significantly compared with that in the inhibitor control group. It indicated that miR-23a played a role in promoting anoxia-induced proliferative activity of PASMCs. The positive rate of the EdU staining result of PASMCs in the transfection mimic control (mimic ctrl) under normoxia, had no significant difference compared with that in the blank control group (vehicle). The positive rate of the EdU staining result of PASMCs in the transfection mimic control (mimic ctrl) at $48 \mathrm{~h}$ after transfection with miR-23a mimic increased significantly compared with that in the mimic control group. It suggested that overexpression of miR-23a under normoxia could also lead to increased proliferation of PASMCs.

Role of HIF-1 $\alpha$ in anoxia-induced upregulation of the $\mathrm{miR}-23 \mathrm{a}$ expression. The expression level of miR-23a in PASMCs transfected with the HIF-1 $\alpha$ specific siRNA under anoxia decreased significantly (Fig. 3A). It indicated that the upregulation of miR-23a under anoxia was regulated by HIF-1 $\alpha$.

The HIF-1 $\alpha$ protein level and the miR-23a expression level in the PASMCs under normoxia in the EDHB $(500 \mu \mathrm{M})$ $24 \mathrm{~h}$ (EDHB, $24 \mathrm{~h}$ ) group increased significantly compared with those in the control group. The expression level of the HIF-1 $\alpha$ protein was significantly higher than that in the control group (vehicle, $48 \mathrm{~h}$ ) and the expression level of miR-23a was significantly higher than that in the control group (vehicle, $48 \mathrm{~h}$ ) at $48 \mathrm{~h}$ after addition of EDHB $48 \mathrm{~h}$ (EDHB, 48 h) (Fig.3B). Changes in the content of pri-miR-23a-1, pri-miR-23a-2, and pri-miR-23a-3 reflected the transcriptional activity of miR-23a-1, miR-23a-2 and miR-23a-3. When PASMCs were cultured under anoxia and transfected with HIF-1 $\alpha$-specific siRNA, the expression levels of pri-miR-23a-1 
A
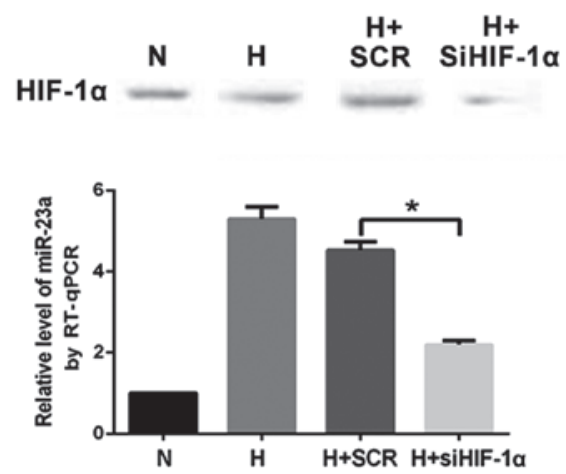

B
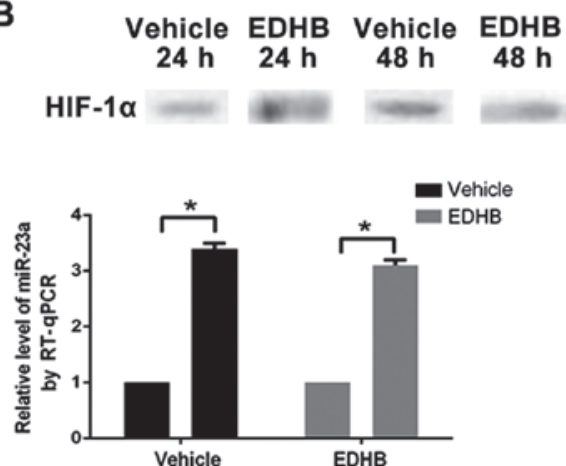

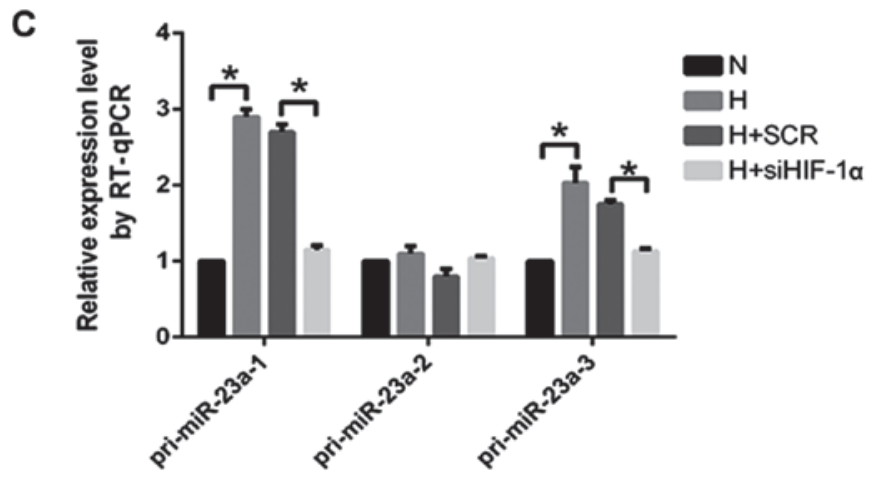

Figure 3. Role of HIF-1 $\alpha$ in anoxia-induced upregulation of miR-23a expression. (A) HIF-1 $\alpha$ mediated upregulation of miR-23a under anoxia, "P $<0.05$. (B) EDHB could upregulate the expression of miR-23a in PASMCs under normoxia, ${ }^{*} \mathrm{P}<0.05$. (C) HIF-1 $\alpha$ mediated the upregulation of the expression of pri-miR-23a-1 and pri-miR-23a-3 under anoxia, ${ }^{*} \mathrm{P}<0.05$. PASMCs, pulmonary artery smooth muscle cells.

and pri-miR-23a-3 decreased significantly (Fig. 3C), indicating that HIF-1 $\alpha$ participated in transcriptional activation effect of miR-23a-1 and miR-23a-3.

HIF-1 1 binding to 5'-UTR of miR-23a-1 and miR-23a-3 and its role in transcriptional activation. The bonding of the three prediction sites (R1, R2 and R3) within the 5'-UTR of miR-23a-1 in PASMCs to HIF-1 $\alpha$ at $24 \mathrm{~h}$ (H24h) and $48 \mathrm{~h}(\mathrm{H} 48 \mathrm{~h})$ after anoxia increased significantly compared with that before anoxia ( $\mathrm{N}$ group). The enrichment level of HIF-1 $\alpha$ in R1 was the highest (Fig. 4A-C). HIF-1 $\alpha$ binding to a binding site $(\mathrm{R})$ within 5 '-UTR of miR-23a-3 in the anoxia $24 \mathrm{~h}$ group $(\mathrm{H} 24 \mathrm{~h})$ and the anoxia $48 \mathrm{~h}$ group $(\mathrm{H} 48 \mathrm{~h})$ increased significantly compared with that in the NC group. To clarify the effect of anoxia and HIF-1 $\alpha$ on the transcriptional activity of miR-23a-1 and miR-23a-3 genes, HEK293FT cells transfected with the wild-type reporter gene vector (WT) or mutant (M1, M2 and M3) reporter gene vector were subjected to anoxia exposure $\left(1 \% \mathrm{O}_{2}\right.$ concentration) treatment and co-transfected with the plasmids with HIF-1 $\alpha$ overexpressed. The result indicated that reporter gene activity of the mutant vectors transfected with M1, M2 and M3 decreased significantly. The reporter gene activity of the mutant vector transfected with M3 had the lowest level (Fig. 4H and I). Anoxia could significantly increase the luciferase activity of the wild-type Luc-miR-23a-1 (WT) but had no effect on the mutant Luc-miR-23a-1M3 (M3) (Fig. 4E). In addition, the wild-type and mutant reporter gene vectors and the plasmids with overexpression of HIF-1 $\alpha$ or the control empty vector were used to co-transfect with the HEK293FT cells. Results showed that the overexpressed HIF-1 $\alpha$ could improve the luciferase activity in the wild-type Luc-miR-23a-1(WT) by 1.8 times but had no effect on the mutant Luc-miR-23a-1M3 (M3) (Fig. 4F). Intervening HIF-1 $\alpha$ could significantly weaken the role of the luciferase activity of the enhanced wild-type Luc-miR-23a-1 (WT) under anoxia (Fig. 4G). For miR-23a-3, anoxia exposure $\left(1 \% \mathrm{O}_{2}\right.$ concentration) and co-transfection with the plasmid with overexpression of HIF-1 $\alpha$ could improve the luciferase activity of the wild-type Luc-miR-23a-3 (WT) by 2.7- and 1.9-fold but had no effect on the mutant Luc-miR-23a-3 (M) (Fig. 4J and K). Intervening with HIF-1 $\alpha$ under anoxia significantly weakened the activity of the wild-type Luc-miR-23a-3 (WT) reporter gene (Fig. 4L). These results indicated that anoxia upregulated the expression of miR-23a-1 and miR-23a-3, which was achieved by the transcriptional activation of HIF- $1 \alpha$.

Effect of chronic anoxia on $m P A P, R V$ weight index, and pulmonary arteriole wall, intima-media thickness, and miR-23a expression. The mean pulmonary arterial pressure in the $\mathrm{CH}$ group increased significantly $(\mathrm{P}<0.05)$, compared with that of the control group (Table I). This suggested that $\mathrm{CH}$ significantly increased the pulmonary arterial pressure. $\mathrm{RV} /(\mathrm{LV}+\mathrm{S})$ in the $\mathrm{CH}$ group increased significantly compared with that in the $\mathrm{NC}$ group $(\mathrm{P}<0.05)$. It indicated that $\mathrm{CH}$ could lead to right ventricle hypertrophy of the rat. We measured the outer diameter and canal wall thickness (outer diameter-inner diameter), and intima-media thickness. The result indicated that the pulmonary arterioles of the rats in the $\mathrm{NC}$ group had 

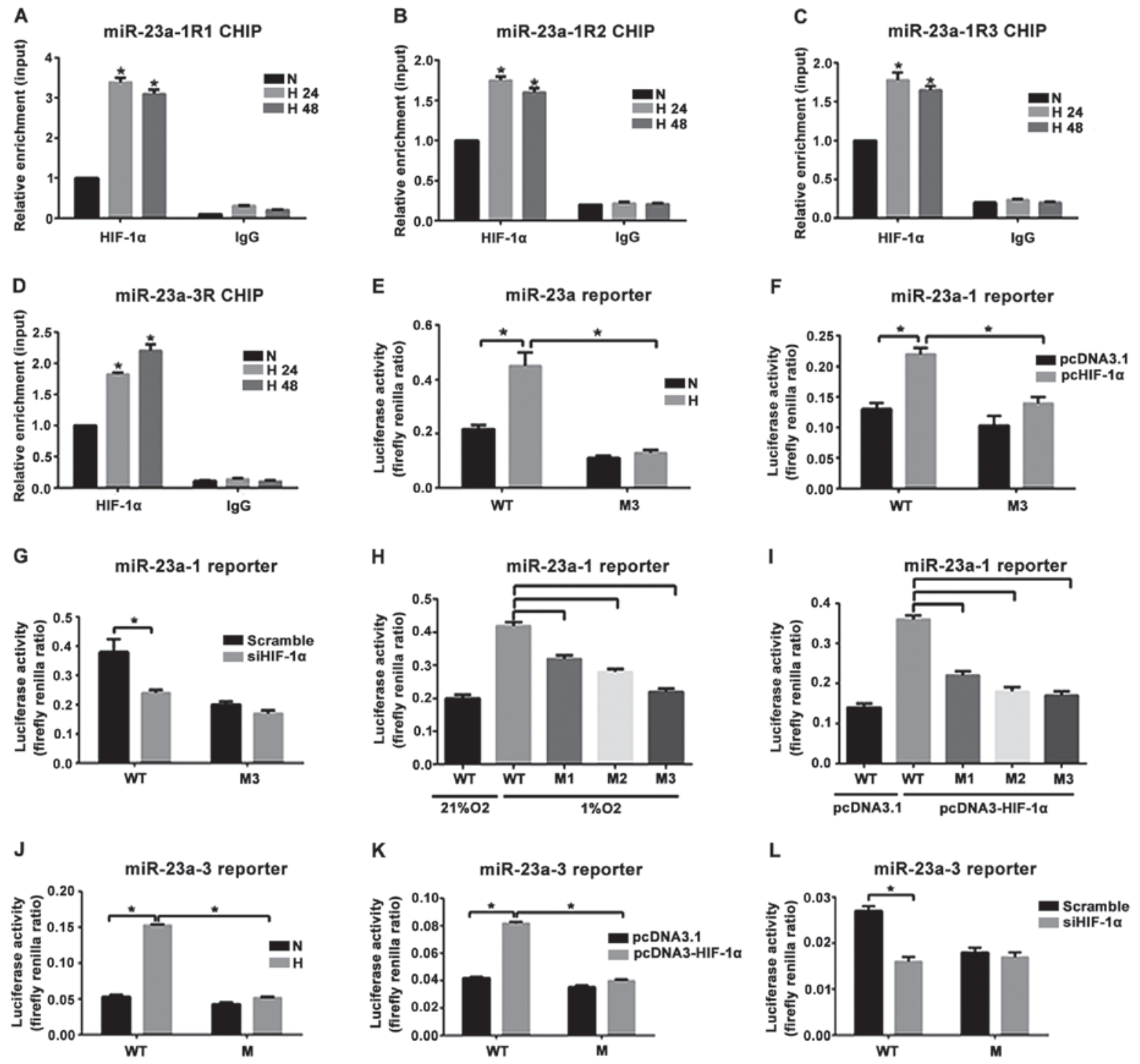

Figure 4. ChIP was used to detect the bonding of HIF-1 $\alpha$ within the upstream $5 \mathrm{~kb}$ region of the transcriptional start site of miR-23a-1 and miR-23a-3 and the effect on transcriptional activation of miR-23a-1 and miR-23a-3 genes following anoxia (A) detecting the bonding of HIF-1 $\alpha$ to miR-23a-1R1 (R1) in the primary PASMCs at 24 and $48 \mathrm{~h}$ after anoxia with ChIP. (B) Bonding of HIF-1 $\alpha$ to miR-23a-1R2 (R2) with ChIP. (C) Detecting the bonding of HIF-1 $\alpha$ to miR-23a-1R3 (R3) with ChIP. (D) Detecting the bonding of HIF-1 $\alpha$ to miR-23a-3R (R) at 24 and $48 \mathrm{~h}$ after anoxia with ChIP, ${ }^{*} \mathrm{P}<0.05$. (E) Effect of anoxia on the activity of the WT and M3 genes of miR-23a-1. (F) Effect of transfection with the plasmid with overexpression of HIF-1 $\alpha$ on the activity of the WT and M3 genes. (G) Effect of transfection with the HIF-1 $\alpha$ specific siRNA on the activity of the WT and M3 reporter genes. (H) Effect of anoxia on the activity of the M1, M2 and M3 reporter genes. (I) Effect of transfection with the plasmid with overexpression of HIF-1 $\alpha$ on the M1, M2 and M3 reporter genes. (J) Effect of anoxia $\left(1 \% \mathrm{O}_{2}\right)$ on the activity of the WT and M reporter genes of miR-23a-3. (K) Effect of transfection with the plasmid with overexpression of HIF-1 $\alpha$ on the activity of the WT and M reporter genes. (L) Effect of transfection with the HIF-1 $\alpha$ specific siRNA on the activity of the WT and M reporter genes. ChIP, chromatin immunoprecipitation; PASMCs, pulmonary artery smooth muscle cells; WT, wild-type; M, mutant.

Table I. Effect of $\mathrm{CH}$ on the mPAP, RV weight index, pulmonary arteriole wall, and intima-media thickness (mean $\pm \mathrm{SD}$ ) of the rats.

\begin{tabular}{lccccc}
\hline Groups & $\begin{array}{c}\text { Mean arterial } \\
\text { pressure }(\mathrm{mmHg})\end{array}$ & $\mathrm{RV}(\mathrm{LV}+\mathrm{S})$ & $\begin{array}{c}\text { Outer diameter } \\
(\mathrm{mm})\end{array}$ & $\begin{array}{c}\text { Canal wall } \\
\text { thickness }(\mathrm{mm})\end{array}$ & $\begin{array}{c}\text { Intima-media } \\
\text { thickness }(\mathrm{mm})\end{array}$ \\
\hline NC group & $16.8 \pm 2.3$ & $0.28 \pm 0.03$ & $81.31 \pm 2.8$ & $10.57 \pm 2.6$ & $3.6 \pm 0.8$ \\
CH group & $33.7 \pm 7.9^{\mathrm{a}}$ & $0.46 \pm 0.06^{\mathrm{a}}$ & $86.61 \pm 6.1$ & $21.3 \pm 4.4^{\mathrm{a}}$ & $8.8 \pm 1.6^{\mathrm{a}}$ \\
\hline
\end{tabular}

${ }^{\mathrm{a}} \mathrm{P}<0.05$ vs. NC. $\mathrm{CH}$, chronic hypoxia; mPAP, mean pulmonary arterial pressure; $\mathrm{RV}$, right ventricular; NC, normoxia control.

thin canal walls and large lumens with an outer diameter of $81.31 \pm 2.8 \mu \mathrm{m}$, canal wall thickness of $10.57 \pm 2.6 \mu \mathrm{m}$, and intima-media thickness of $3.6 \pm 0.8 \mu \mathrm{m}$ (Table I). The outer diameter of pulmonary arterioles in the $\mathrm{CH}$ group was $86.61 \pm 6.1 \mu \mathrm{m}$, canal wall thickness was $21.3 \pm 4.4 \mu \mathrm{m}$, and intima-media thickness was $8.8 \pm 1.6 \mu \mathrm{m}$. It indicated that $\mathrm{CH}$ 


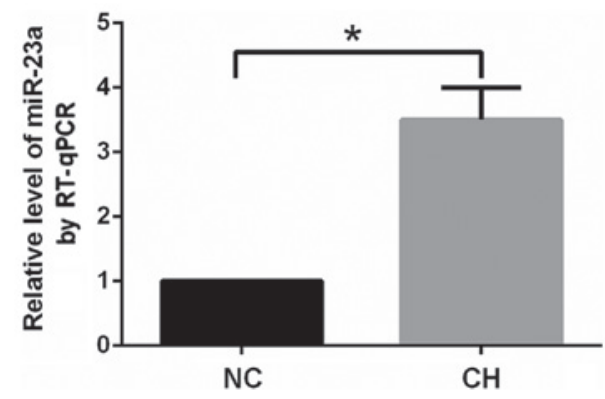

Figure 5. Effect of $\mathrm{CH}$ on the expression of miR-23a in the rat pulmonary arterioles. ${ }^{*} \mathrm{P}<0.05$ vs. NC. $\mathrm{CH}$, chronic hypoxia; NC, normoxia control.

could significantly increase the thickness of the pulmonary arteriole wall and lead to proliferation of the medial smooth muscle cells and structure remodeling of the pulmonary arterioles. The expression of miR-23a in the pulmonary arterioles in the $\mathrm{CH}$ group increased significantly $(\mathrm{P}<0.05)$ compared with that in the NC group (Fig. 5).

\section{Discussion}

The pulmonary arteriole canal wall comprises endothelial cells, smooth muscle cells and fibroblasts. PASMCs are the major effector cells during the systolic process of the pulmonary arterioles due to hypoxia $(18,19)$ and the key cells participating in pulmonary vascular structural remodeling during the $\mathrm{CH}$ process. Previous studies have shown that hypoxia is significant in in vitro primary PASMCs (20). In the experiment involving detection of the proliferative activity of PASMCs with EdU staining, it was found that the positive rate of the EdU staining results of PASMCs improved significantly at $48 \mathrm{~h}$ after exposure to $3 \% \mathrm{O}_{2}$ hypoxia, suggesting that hypoxia enables the proliferative activity of PASMCs to improve. It has been shown that the proliferative activity of PASMCs decreased significantly following exposure to $1 \% \mathrm{O}_{2}$ hypoxia, suggesting that hypoxia can also inhibit cell proliferation (21). Thus, the effect of hypoxia on the proliferative activity of PASMCs is closely associated with oxygen concentration.

Other studies showed that the phenotypic transformation of VSMCs occurs earlier than the cellular proliferation and migration, and the phenotypic transformation of VSMCs is often accompanied with changes in the expression of the phenotypic specific marker protein (22). There is also evidence suggesting that multiple stimulations could cause phenotypic transformation in VSMCs (23). Serum stimulation and hunger can influence the expression of the contractile phenotype markers in VSMCs cultures (24). Hunger can upregulate the phenotypic marker expression in VSMCs thus enabling VSMCs to have contractile phenotype. Under the simulations of multiple types of cytokines and growth factors, VSMCs can also transform from the differentiated phenotype with a systolic function into de-differentiated phenotype with migration and proliferation abilities. The present study found that the exposure to hypoxia for 24 or $48 \mathrm{~h}$ downregulated the expression of phenotypic marker proteins in PASMCs. However, we need to study this phenomenon further to understand the mechanism controlling this downregulation.
miR-23a is extensively expressed in different animals, and its gene sequence is highly conserved. In the mammals, miR-23a is mainly expressed in the nerve tissue, particularly, in the process of the nervous system development, however, later it maintains at a relatively low expression level. Changes in the expression level of miR-23a are closely associated with activities such as proliferation and migration of neurocytes. Prior studies have discovered that miR-23a is expressed abnormally in multiple tumors and closely associated with the occurrence and progression of tumors. It regulates tumor proliferation, apoptosis, metastasis and invasion $(13,15)$. In the present study, we conducted gain-of-function and loss-of-function experiments by transfecting cells with chemosynthetic miR-23a-mimic and miR-23a inhibitor. We obtained results suggesting that the expression levels of the contractile marker proteins increased significantly after transfection with miR-23a inhibitor under hypoxia compared with those in the inhibitor control group. Positive rate of the EdU staining in PASMCs decreased significantly. In addition, transfection with miR-23a mimic downregulated the expression of contractile marker proteins in PASMCs and strengthened the proliferative activity under normoxia.

We demonstrated that miR-23a also played an important role in regulating the anoxia-induced phenotypic transformation in PASMCs. The expression level of miR-23a in PASMCs decreased significantly when the cells were transfected with the HIF-1 $\alpha$ specific siRNA under hypoxia, indicating that the upregulation of miR-23a under hypoxia was regulated by HIF-1. The levels of pri-miR-23a-1 and pri-miR-23a-3 in PASMCs increased significantly after hypoxia treatment while the expression level of pri-miR-23a-2 did not change significantly, suggesting that hypoxia can improve the transcription of miR-23a-1 and miR-23a-3. The expression levels of pri-miR-23a-1 and pri-miR-23a-3 were inhibited while the expression level of pri-miR-23a-2 did not change significantly after PASMCs were transfected with the HIF-1 $\alpha$ specific siRNA under hypoxia, indicating that HIF-1 $\alpha$ participates in anoxia-induced upregulation of the expression of miR-23a-1 and miR-23a-3.

HIF-1 $\alpha$ binding to its target sites under hypoxia was detected with the ChIP-qPCR method. Results indicated that HIF-1 $\alpha$ binding to its target sites within 5'-UTR of miR-23a-1 in PASMCs increased significantly at 24 and $48 \mathrm{~h}$ after hypoxia.

The dual-luciferase reporter gene experiment result indicated that the regulatory region containing the HIF-1 binding sequence upstream of miR-23a-1 and miR-23a-3 exerted its strengthened sub-functions. The hypoxia environment plays a role in activating the transcription of miR-23a-1 and miR-23a-3 by increasing rate of HIF-1 $\alpha$ binding to the $c i$-acting elements. The above mentioned results demonstrated that the mechanism of hypoxia in upregulating the expression of miR-23a in PASMCs may be caused by the role of HIF-1 $\alpha$ in activating the transcription of miR-23a-1 and miR-23a-3. Differences in HIF-1 $\alpha$ binding rate among the miR-23a-1, miR-23a-2 and miR-23a-3 regions may be the internal mechanism responsible for the different transcriptional levels of various encoding genes of miR-23a under hypoxia.

Rats were put in the low-pressure hypoxia animal chamber at a simulated altitude of $5,000 \mathrm{~m}$ and exposed to $\mathrm{CH}$ for 
21 days to replicate the HPH models. The experimental results suggested that the pulmonary arterial pressure rose significantly at 21 days after $\mathrm{CH}$. Pulmonary arteriole vascular wall and tunica media vasorum thickness increased significantly and a series of morphological changes including structural reconstruction and right ventricle hypertrophy occurred. These results were consistent with the results obtained in a previous study (25). Hypoxia significantly increased the expression of miR-23a in the pulmonary arteriole compared with normoxia, indicating that miR-23a may be involved in regulating the hypoxic pulmonary vascular remodeling. Regulating the miR-23a expression may become one of the effective therapeutic approaches for targeted therapy of $\mathrm{HPH}$.

In conclusion, we have demonstrated that miR-23a played an important role in anoxia-induced phenotypic transformation in PASMCs. Future studies are to investigate whether miR-23a can participate in such functional changes as anoxiainduced apoptosis, secretion and migration. We detected the expression of miR-23a in rat pulmonary arterial tissue with $\mathrm{CH}$ and discovered changes in miR-23a level following $\mathrm{CH}$. However, further research should be conducted to investigate whether miR-23a can sufficiently influence the occurrence of $\mathrm{HPH}$ in rats.

\section{Acknowledgements}

The present study is funded by the project: Major Medical Research Program of Health Department of Hebei Province (20110012).

\section{References}

1. Bishop T and Ratcliffe PJ: HIF hydroxylase pathways in cardiovascular physiology and medicine. Circ Res 117: 65-79, 2015.

2. Wilkins MR, Ghofrani HA, Weissmann N, Aldashev A and Zhao L: Pathophysiology and treatment of high-altitude pulmonary vascular disease. Circulation 131: 582-590, 2015.

3. Shovlin CL: Pulmonary arteriovenous malformations. Am J Respir Crit Care Med 190: 1217-1228, 2014.

4. Hu J, Xu Q, McTiernan C, Lai YC, Osei-Hwedieh D and Gladwin M: Novel targets of drug treatment for pulmonary hypertension. Am J Cardiovasc Drugs 15: 225-234, 2015.

5. Vaillancourt M, Ruffenach $G$, Meloche $J$ and Bonnet S: Adaptation and remodelling of the pulmonary circulation in pulmonary hypertension. Can J Cardiol 31: 407-415, 2015.

6. Lai N, Lu W and Wang J: $\mathrm{Ca}(2+)$ and ion channels in hypoxia-mediated pulmonary hypertension. Int J Clin Exp Pathol 8: 1081-1092, 2015.
7. Jernigan NL: Smooth muscle acid-sensing ion channel 1: pathophysiological implication in hypoxic pulmonary hypertension. Exp Physiol 100: 111-120, 2015.

8. Lee A, McLean D, Choi J, Kang H, Chang W and Kim J: Therapeutic implications of microRNAs in pulmonary arterial hypertension. BMB Rep 47: 311-317, 2014.

9. Ishii T, Warabi E, Siow RC and Mann GE: Sequestosome1/p62: a regulator of redox-sensitive voltage-activated potassium channels, arterial remodeling, inflammation, and neurite outgrowth. Free Radic Biol Med 65: 102-116, 2013.

10. Yamamura A, Yamamura $\mathrm{H}$ and Yuan JX: Enhanced $\mathrm{Ca}^{2+}$-sensing receptor function in pulmonary hypertension. Yakugaku Zasshi 133: 1351-1359, 2013 (In Japanese).

11. Saito Y, Nakamura K, Akagi S, Sarashina T, Ejiri K, Miura A, Ogawa A, Matsubara $\mathrm{H}$ and Ito $\mathrm{H}$ : Epoprostenol sodium for treatment of pulmonary arterial hypertension. Vasc Health Risk Manag 11: 265-270, 2015.

12. Wang XH: MicroRNA in myogenesis and muscle atrophy. Curr Opin Clin Nutr Metab Care 16: 258-266, 2013.

13. Henshall DC: MicroRNA and epilepsy: profiling, functions and potential clinical applications. Curr Opin Neurol 27: 199-205, 2014.

14. Kunz M: MicroRNAs in melanoma biology. Adv Exp Med Biol 774: 103-120, 2013.

15. Han M, Toli J and Abdellatif M: MicroRNAs in the cardiovascular system. Curr Opin Cardiol 26: 181-189, 2011.

16. Chhabra R, Dubey R and Saini N: Cooperative and individualistic functions of the microRNAs in the miR-23a 27a 24-2 cluster and its implication in human diseases. Mol Cancer 9: 232, 2010.

17. Dang CV: Rethinking the Warburg effect with Myc micromanaging glutamine metabolism. Cancer Res 70: 859-862, 2010.

18. Huetsch $\mathrm{J}$ and Shimoda LA: $\mathrm{Na}(+) / \mathrm{H}(+)$ exchange and hypoxic pulmonary hypertension. Pulm Circ 5: 228-243, 2015.

19. West JB: High-altitude medicine. Am J Respir Crit Care Med 186: 1229-1237, 2012.

20. Killilea DW, Hester R, Balczon R, Babal P and Gillespie MN: Free radical production in hypoxic pulmonary artery smooth muscle cells. Am J Physiol Lung Cell Mol Physiol 279: L408-L412, 2000.

21. Yamamura A: Pathological function of $\mathrm{Ca}^{2+}$-sensing receptor in pulmonary arterial hypertension. J Smooth Muscle Res 50: 8-17, 2014.

22. Jernigan NL and Resta TC: Calcium homeostasis and sensitization in pulmonary arterial smooth muscle. Microcirculation 21: 259-271, 2014.

23. Kuhr FK, Smith KA, Song MY, Levitan I and Yuan JX: New mechanisms of pulmonary arterial hypertension: role of $\mathrm{Ca}^{2+}$ signaling. Am J Physiol Heart Circ Physiol 302: H1546-H1562, 2012.

24. Dang CV, Le A and Gao P: MYC-induced cancer cell energy metabolism and therapeutic opportunities. Clin Cancer Res 15: 6479-6483, 2009.

25. Sutendra G and Michelakis ED: The metabolic basis of pulmonary arterial hypertension. Cell Metab 19: 558-573, 2014. 